\title{
Laser Ablation/Ionisation Mass Spectrometry: Sensitive and Quantitative Chemical Depth Profiling of Solid Materials
}

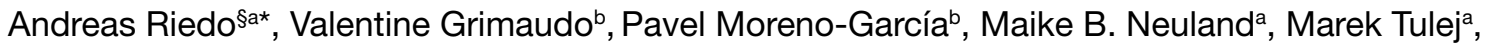 \\ Peter Broekmann ${ }^{\mathrm{b}}$ and Peter Wurz ${ }^{\mathrm{a}}$
}

§SCS-Metrohm Award for best oral presentation in Analytical Sciences

\begin{abstract}
Direct quantitative and sensitive chemical analysis of solid materials with high spatial resolution, both in lateral and vertical direction is of high importance in various fields of analytical research, ranging from in situ space research to the semiconductor industry. Accurate knowledge of the chemical composition of solid materials allows a better understanding of physical and chemical processes that formed/altered the material and allows e.g. to further improve these processes. So far, state-of-the-art techniques such as SIMS, LA-ICP-MS or GD-MS have been applied for chemical analyses in these fields of research. In this report we review the current measurement capability and the applicability of our Laser Ablation/lonisation Mass Spectrometer (instrument name LMS) for the chemical analysis of solids with high spatial resolution. The most recent chemical analyses conducted on various solid materials, including e.g. alloys, fossils and meteorites are discussed.
\end{abstract}

Keywords: Chemical depth profiling · Chemical mapping of heterogeneous materials .

High spatial resolution analysis · Laser ablation - Laser ionisation mass spectrometry

\section{Introduction}

Sensitive chemical analysis of solid materials with high spatial resolution in the micro- and nanometre regime is of considerable interest and importance in various fields of academic and industrial research. These include e.g. the chemical analysis of layered solar panels, ${ }^{[1,2]}$ the analysis of space-weathered samples, ${ }^{[3]}$ the investigations of contaminants embedded within electrodeposited $\mathrm{Cu}$ interconnects ${ }^{[4,5]}$ and extensive chemical analyses of corroded glass, ${ }^{[6]}$ ancient celadon ${ }^{[7]}$ or geological samples, ${ }^{[8]}$ among many others. In comparison to bulk analyses, measurement techniques with high spatial resolution enable detailed chemical insights into the sample material and provide better understanding of physical and chemical processes that may have fashioned or modified the analyte of interest.

\footnotetext{
${ }^{*}$ Correspondence: Dr. A. Riedo ${ }^{a}$

E-mail: andreas.riedo@space.unibe.ch

aPhysics Institute, Space Research and Planetary Sciences

University of Bern

Sidlerstrasse 5, CH-3012 Bern, Switzerland

bepartment of Chemistry and Biochemistry

Interfacial Electrochemistry Group

University of Bern

Freiestrasse 3, CH-3012 Bern, Switzerland
}

Various sensitive and high-resolution measurement techniques available nowadays on the market, such as Auger Electron Spectroscopy (AES), ${ }^{[9,10]}$ X-ray Photoelectron Spectroscopy (XPS), ${ }^{[9,11]}$ Secondary Ion Mass Spectrometry (SIMS) ${ }^{[5,9]}$ and Secondary Neutron Mass Spectroscopy (SNMS), ${ }^{[12]}$ Glow Discharge Time-of-Flight Mass Spectrometry (GDTOF-MS $)^{[1,9]}$ or Laser Ablation Inductively Coupled Plasma Mass Spectrometry (LAICP-MS $)^{[2,6,9]}$ are widely applied for the understanding of the above listed questions concerning the chemical composition of solid materials. Each analytical technique differs in its measurement capabilities and limitations, including e.g. its detection sensitivity (e.g. mass spectroscopic versus mass spectrometric), quantitative nature of conducted measurements (e.g. SIMS versus LA-ICP-MS), lateral profiling capabilities (e.g. SIMS versus GD-TOF-MS), vertical profiling capabilities (SIMS versus LA-ICP-MS), measurement speed acquisition (e.g. XPS versus GD-TOF-MS), time for data interpretation (GD-TOF-MS versus AES), or limitations concerning the suitable sample shape. ${ }^{[9,12]}$ Therefore, typically a combination of diverse measurement techniques is required to provide detailed insights into the sample material and hence, to answer the scientific questions of interest.
With advances in vacuum technology, improved high speed electronics (e.g. data acquisition system) and laser systems with significantly increased performance, Laser Ablation/Ionisation Mass Spectrometry (LIMS) has proved, in the last decade, to be a truly alternative measurement technique for the sensitive and quantitative chemical investigation of solid materials with high spatial resolution and figures of merit comparable to state-of-the-art measurement techniques, such as SIMS, LA-ICP-MS or GD-TOF-MS.[4,7,13-16] The implementation of ultrafast pulsed laser systems used as ablation and ionisation source with pulse widths within the femtosecond regime and pulse to pulse energy stability better than the \%-level (e.g. CPA system, Clark-MXR Inc., USA) has allowed the measurement performance and capabilities of LIMS to be significantly increased. ${ }^{[4,14,17]}$ In comparison to laser systems providing longer pulses the application of a femtosecond laser ablation/ionisation source has various analytical advantages, including e.g. minimised elemental fractionation due to reduced thermal heating of the sample material (heat affected zone, HAZ) ${ }^{[18]}$ and the lack of interaction between the ejected plasma during the laser ablation process and the laser pulse. ${ }^{[19,20]}$ Another important advantage concerns the improved stoichiometry and ionisation efficiency of 
the elements, ${ }^{[14,17]}$ which together with the ability of clean material ablation ${ }^{[19-22]}$ and high pulse-to-pulse reproducibility enable a laser ablation in a highly controlled manner. ${ }^{[4,17]}$

So far, various LIMS systems have been designed and constructed specifically to investigate different scientific questions and for the application in variable environments, ranging from elemental mapping $[8,23]$ to depth profiling analyses, ${ }^{[4,16]}$ from laboratory ${ }^{[7,8,12,14-16,24,25]}$ instruments to instruments with the capability to operate on planetary objects. ${ }^{[17,26-31]}$ However, and to our best current knowledge, only the designs from the research groups of Huang, ${ }^{[8,14,15,24]}$ Cui et al., ${ }^{[16]}$ and Wurz, ${ }^{[4,13,17,23,32]}$ have reached the measurement capabilities and performance comparable to the state-of-the-art measurement techniques for chemical analysis with high spatial resolution. All these systems consist of a TOF mass analyser, a sophisticated detector system and are equipped with a femtosecond laser ablation/ionisation source and differ only in their technical realisation. In the following the LIMS systems from Cui et al. ${ }^{[16]}$ and the Huang group ${ }^{[8,14,15,24]}$ are discussed only briefly. Readers should consult the listed references for further information. To introduce the reader in more detail to the LIMS measurement technique, the performance and principles of operation of the LIMS system developed in our group are discussed in more detail afterwards.

The LIMS system from the Huang group (MCP detector system in chevron configuration, dynamic range of about 6-7 orders of magnitude, lateral resolution of about $40 \mu \mathrm{m}$ ) is based on an orthogonal ion source design (the principal axis of the laser ablation/ionisation ion source is orthogonal to the principal ion optical axis of the mass spectrometer) and consists of a reflectron-type time-of-flight (TOF) mass spectrometer. ${ }^{[8,14,15,24]}$ In comparison to the other LIMS systems, inert buffer gas such as $\mathrm{He}$ or Ar is used for collisional cooling of energetic ions from the ablation process as well as charge reduction of multiple charged ions produced during the laser $a b-$ lation process. ${ }^{[15,33]}$ The system has a detection sensitivity down to $30 \mathrm{ppb}(\mathrm{g} / \mathrm{g}, \mathrm{Li})$ but due to contaminants within the buffer gas sensitivities for a few elements, e.g. C, $\mathrm{N}$ or $\mathrm{O}$, rises to few hundreds of ppm. ${ }^{[8,24]}$ So far, the system has been used for chemical mapping of solids with high lateral resolution ${ }^{[8]}$ and no depth profiling studies were carried out, to the best of our knowledge. In the LIMS system from Cui et al. (MCP detector system in chevron configuration), laser ablation is realised by the laser hitting the sample at a $60^{\circ}$ incident angle, instead of perpendicular incidence, which results in an elliptical ablation spot and crater. ${ }^{[16]}$ Depending on the applied laser irradiance the dimension of the crater in one direction is about $5 \mu \mathrm{m}$, and shows an increased dimension in the other axis. An integrated ion funnel and a differential pumping system allow the ion source to be operated at pressures up to about 0.3 mbar. This latter LIMS system can be used for elemental imaging with a lateral resolution on the $\mu \mathrm{m}$-scale but also for chemical depth profiling studies with a resolution of about $6 \mathrm{~nm} .^{[8]}$

The LIMS system developed by the group of Wurz (instrument name LMS) was originally designed for in situ investigation of the chemical composition of solids on planetary objects, for a lander platform on-board ESA's BepiColombo space mission for the detailed exploration of Mercury's surface. ${ }^{[26]}$ Unfortunately, the lander platform was cancelled later on due to budgetary reasons but since its first design in 2003 LMS has been continuously further developed. ${ }^{[4,13,17,32-42]}$ Today, LMS represents the most powerful and versatile LIMS system ever designed for in situ space investigations and exhibits top performing figures of merit. The system has the capability to conduct quantitative measurements with high detection sensitivity (10 ppb, atomic fraction) and with a dynamic range of about eight orders of magnitude. ${ }^{[17,37]}$ It allows measurements of element isotopes with high accuracy, ${ }^{[38]}$ enables the elemental imaging of heterogeneous materials with micrometre resolution, ${ }^{[23,32,35,36]}$ and provides high vertical depth profiling capabilities with sub-nanometre resolution. ${ }^{[4,13]}$ The measurement capabilities of LMS for elemental imaging and depth profiling of solid materials are presented in more detail in section 3, where most recent and current measurements conducted on different sample materials, including the chemical mapping of an Allende meteorite sample, depth profiling of Si-supported $\mathrm{Cu}$ layers, chemical analysis of micrometre fossils embedded in an argonite matrix, and capabilities towards 3D elemental imaging of bronze-alloy samples are presented.

\section{Experimental Setup}

LMS is a reflectron-type time-of-flight (RTOF) mass spectrometer and was originally designed for in situ measurements on planetary objects. The principles of operation and technical scheme of LMS are briefly discussed in the following. Detailed information of the current setup can be found in recent publications. ${ }^{[4,17,26,37]}$

Since parameters such as size, power consumption and mass are highly limited on a spacecraft the LMS mass analyser has the dimensions of only $160 \mathrm{~mm} \times 60 \mathrm{~mm}$.
In the current setup an ultrafast pulse laser system $(\lambda=775 \mathrm{~nm}, \tau \sim 190 \mathrm{fs}$, repetition rate $\leq 1 \mathrm{kHz}$, intensity $\leq 1 \mathrm{~mJ} /$ pulse, CPA system, Clark-MXR Inc., USA) is used as ablation/ionisation source and is positioned outside the vacuum chamber. ${ }^{[17]}$ Laser pulses are guided towards the vacuum chamber by dielectric mirrors, pass the entrance window of the vacuum chamber and are focused through the mass analyser towards the sample surface using a lens system installed right on top of the mass analyser. The current lens system allows circular laser ablation generating a crater diameter in the range of about $10-15 \mu \mathrm{m} .{ }^{[4]}$ Samples are positioned about $1 \mathrm{~mm}$ away from the entrance of the LMS by using a high resolution xyz-micro translational stage with a position accuracy of about $2 \mu \mathrm{m}$. Only positively charged ions, generated during the ablation/ionisation process, can enter the ion optical system of LMS where they are subsequently accelerated, focussed and confined in the field free drift tube. The ions are finally reflected by the ion mirror towards the detector system by passing the field free drift tube a second time. In Fig. 1 the scheme and principles of operation of LMS are shown. Mass separation occurs along the ion trajectory because of the different velocity of different mass ions, having the same energy and the ions arrive at the detector system in sequence of their mass-to-charge ratio $(\mathrm{m} / \mathrm{z})$. A multi-readout multi-channel plate

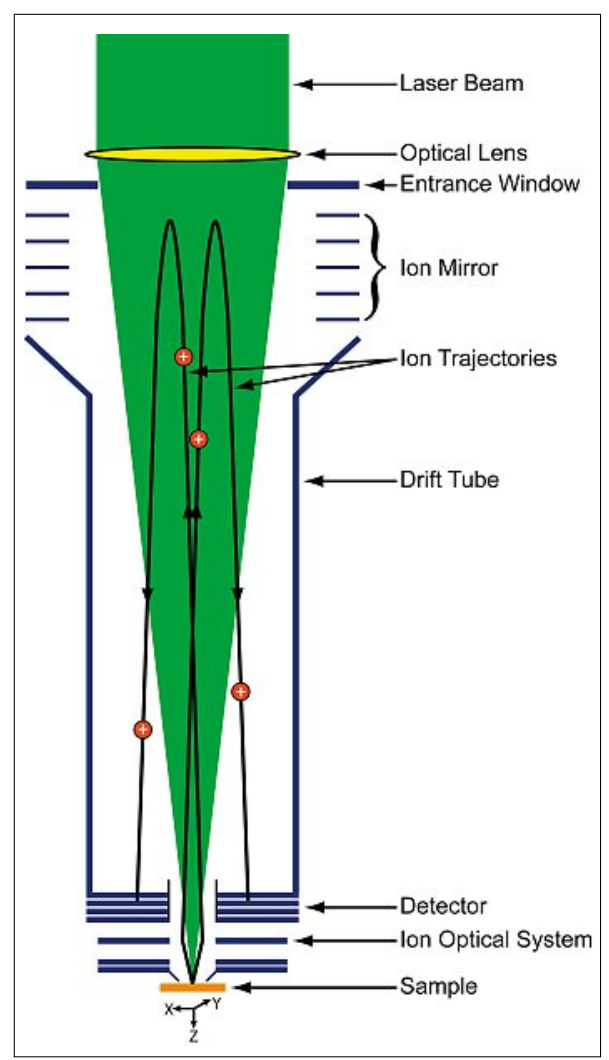

Fig. 1. Simplified schematic drawing of our LMS instrument showing briefly its principle of operation. 
(MCP) detector system in chevron configuration (stack of 2 MCP plates) is used for the detection of the incoming ions. The special design of the detector system and the multi-readout of signals allow measurements to be conducted with a high dynamic range of about eight orders of magnitude and hence, allow signals from major to trace elements to be measured simultaneously. Two high speed ADC cards ( 8 bit, 2 channels each, up to $4 \mathrm{GS} / \mathrm{s}$ ) are used to record the electrical signals generated by the MCP detector system.

The laser system (initiation, energy/ pulse, number of single laser shots), the micro translational stage and the acquisition system are controlled fully remotely by a custom-made software package. The remote access to these units allows measurements with specific needs to be conducted, such as single spot measurements or rastering over a complete sample surface stepwise or continuously, including the acquisition of single laser shot mass spectra. ${ }^{[4,13,17,23,32,36]}$

\section{Measurement Examples and Discussions}

The studies presented in the following are a set of examples of what has been achieved so far with the LMS. Additionally, current research on a wide variety of materials is being carried out to further demonstrate the capabilities and versatility of LMS.

\subsection{Two-dimensional Elemental Imaging of an Allende Meteorite Fragment}

Fig. 2 shows a composite microscope image of an Allende meteorite sample, a highly heterogeneous extra-terrestrial material, composed of matrix material and various chondrules and inclusions. ${ }^{[23]}$ The Allende sample was selected for mass spectrometric investigations using LMS to demonstrate the performance of the instrument for in situ chemical analysis of heterogeneous samples on planetary objects, such as planets, moons, and asteroids. The measurements demonstrate the capability of LMS to provide chemical maps of highly heterogeneous materials. Chemical analyses were conducted using two different laser systems, a nanosecond laser system $(\lambda=266 \mathrm{~nm}, \tau \sim 3 \mathrm{~ns}$, pulse repetition rate of $20 \mathrm{~Hz}$, ablation crater of $\sim 20 \mu \mathrm{m}$ in diameter, $\left.\leq 1 \mathrm{GW} / \mathrm{cm}^{2}\right)^{[23]}$ and a femtosecond laser system $(\lambda=775 \mathrm{~nm}, \tau \sim 190 \mathrm{fs}$, pulse repetition rate of $1 \mathrm{kHz}$, ablation crater of $\sim 12 \mu \mathrm{m}$ in diameter, $\sim 30 \mathrm{TW} / \mathrm{cm}^{2}$ ). Mass spectrometric measurements were conducted on 138 single surface positions with a horizontal and vertical spacing of $600 \mu \mathrm{m}$ and $426 \mu \mathrm{m}$ respectively, using the nanosecond laser system. In this measurement campaign 500 single waveforms per analysed location were acquired, each an accumulation of 100 single laser shot mass spectra (50'000 single laser shots were applied). Detailed information on the measurements can be found in ref. [23]. Subsequently, a dense raster of $63 \times 13$ single surface positions (spacing of $50 \mu \mathrm{m}$ ) using the femtosecond laser system was conducted (black rectangle in Fig. 2). On each surface position 30 waveforms were acquired, each an accumulation of 2'000 single laser shot mass spectra (60'000 single laser shots were applied), and analysed.

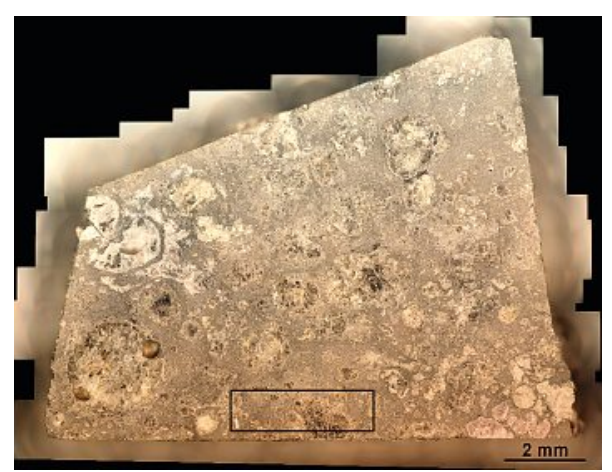

Fig. 2. Composite microscope image of an Allende meteorite sample. The surface area surrounded by the black rectangle was investigated spot-wise in detail by LMS using the femtosecond laser system (see Fig. 3).

Fig. 3 presents the high resolution elemental mapping (preliminary analysis) of the selected Allende surface area (black frame) conducted using the femtosecond laser system. In panel a) the investigated surface area (Fig. 2) is magnified and several inclusions are visible; the three most distinct inclusions are marked in black (A1 and A2). Panels b) - d) illustrate the abundance distribution for $\mathrm{Cr}, \mathrm{S}$, and $\mathrm{Fe}$, respectively. While within the areas A1 and A2 Fe and $\mathrm{S}$ are less abundant, a higher abundance of Cr was measured at the boundary of area A1. In general, mass spectrometric investi- gations of Allende, so far, were conducted separately on specifically selected sample material, such as chondrules or CAIs (CaAl-rich inclusions) that were mechanically extracted by dedicated tools for the purpose of measurement. ${ }^{[e . g .43,44]}$ The elemental mapping using LMS, however, allows the chemical composition of Allende to be quantified without any dedicated sample preparation. Furthermore, by knowing the chemical composition of many surface positions on any geological sample, a mineralogical bulk analysis of the sample can be provided. Fig. 4 presents the mineralogical analysis resulting from the LMS measurements on Allende conducted with the nanosecond laser system. The measurements are in good agreement with the expected elemental composition of the meteorite. In this campaign most measurements represent mixtures of known minerals, which can be explained by the small size of mineral grains and the comparably larger size of the laser spot. Therefore, the collectivity of the 138 measurement points is in good agreement with the literature Allende bulk composition. ${ }^{[23]}$

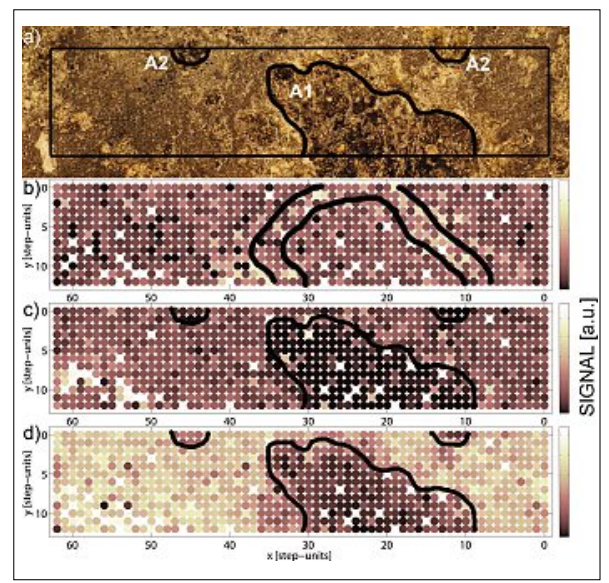

Fig. 3. Spot-wise chemical investigation $(13 \times 63$ single surface positions) of a sample of Allende meteorite using LMS. a) Detail of rectangular section from Fig. 2, element map of b) $\mathrm{Cr}, \mathrm{c}$ ) $\mathrm{S}$, and d) $\mathrm{Fe}$.

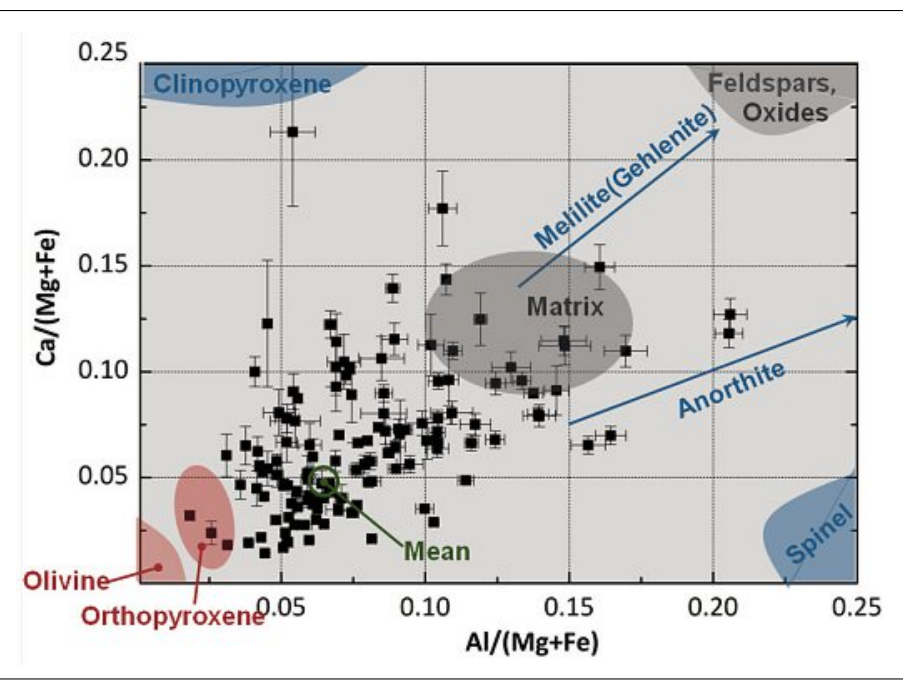

Fig. 4. Mineralogical analysis of Allende as a result of measurements conducted with the nanosecond laser system. Literature mean (in green) from Stracke et al. ${ }^{[45]}$ and McSween and Huss. ${ }^{[46]}$

Reprinted from Neuland et al. ${ }^{[23]}$ Copyright (2016), with permission from Elsevier. 


\subsection{Chemical Analysis with Sub- nanometre Vertical Resolution}

Single laser shot mass spectrometric measurements were conducted on $\mathrm{Cu}$ samples with defined thickness (typically 10 $\mu \mathrm{m})$ to investigate the correlation between laser pulse energies (laser irradiances) and resulting mean ablation rate, that is the ratio between layer thickness and number of applied single laser shots needed to perforate the layer. ${ }^{[4]}$ The $\mathrm{Cu}$ was electrochemically deposited on a $\mathrm{Si}$-supported $\mathrm{Cu}$ seed layer under galvanostatic conditions in the presence of different plating additives (SPS, Imep, PEI, and PAG). ${ }^{[4]}$ The femtosecond laser system was used as ablation/ionisation source and laser pulses were focussed onto the sample surface with a diameter of about $14 \mu \mathrm{m}$. For the first time quantitative mass spectrometric depth profiles with a mean ablation rate at the sub-nanometre regime were achieved by applying the LIMS measurement technique (Fig. 5).

Fig. 6 demonstrates the quantitative depth profiling capability of LMS. It shows a depth profile section of a multi-layered $\mathrm{Cu}$ film (sample S4), where the abundances of the major contaminant $\mathrm{C}, \mathrm{N}$ and $\mathrm{O}$, mainly originating from the electroplating additives SPS and Imep, are monitored with sub-nanometre resolution. ${ }^{[4]}$ These additives are applied to improve the copper electrodeposition of interconnects. However, under specific electrochemical conditions they can form quasi-periodic embedded contamination layers inside the $\mathrm{Cu}$ film. ${ }^{[4,5,47-50]}$ The sharp increase and subsequent decrease of the $\mathrm{C}, \mathrm{N}$ and $\mathrm{O}$ signals are in phase and exhibit anti-correlated intensity oscillations with the recorded $\mathrm{Cu}$ signal, as was expected from previous depth profiling experiments obtained with the SIMS technique. However, in contrast to traditional SIMS measurements, the LMS measurements neither showed attenuation nor broadening of these oscillations with increasing material erosion, indicating a smoother ablation procedure and negligible roughening effects at the crater bottom.

\subsection{Micrometre-size Fossils Embedded in an Argonite Matrix}

Fig. 7 shows microscope images of a geological sample with embedded fossils within an argonite matrix. Mass spectrometric measurements were conducted within the square M1 $\left(200 \times 200 \mu \mathrm{m}^{2}\right)$, marked in panel a) and enlarged in panel b). The area of interest was investigated spot-wise by a raster of $10 \times 10$ surface positions with a spacing of $20 \mu \mathrm{m}$. From each single surface position 20 waveforms were recorded, each an accumulation of 2'000 single laser shot mass spectra (40'000 single laser shot mass spectra in total), which corresponds to a depth resolution of about

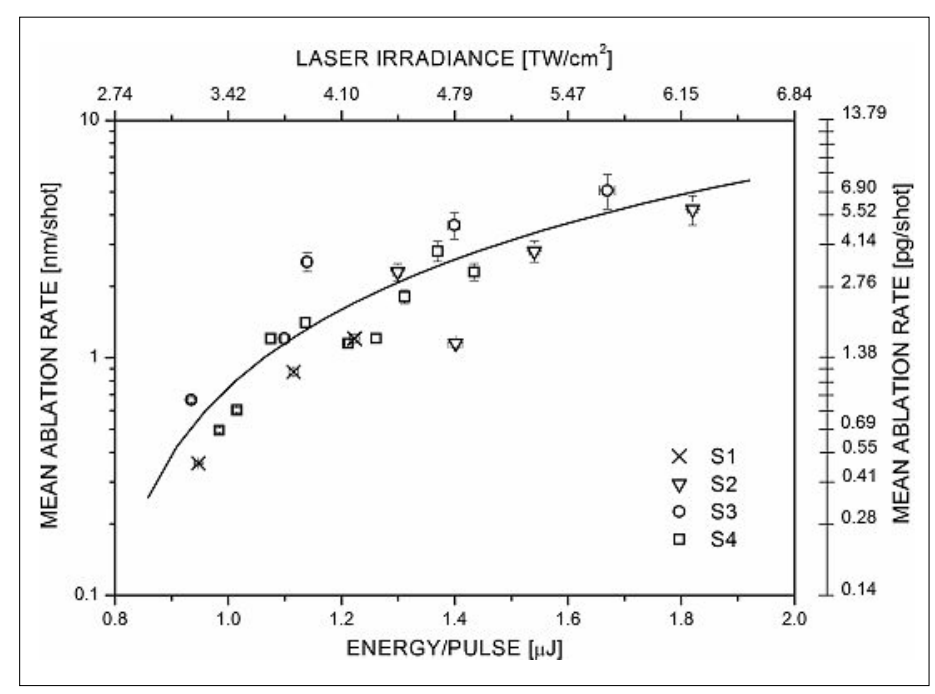

Fig. 5. Correlation between mean ablation rate and applied pulse energy (laser irradiance). For the first time quantitative mass spectrometric measurements with sub-nanometer resolution per single laser shot were realized using the LIMS measurement technique. ${ }^{[4]}$ Reprinted with permission from Grimaudo et al.[4] Copyright (2016) American Chemical Society.

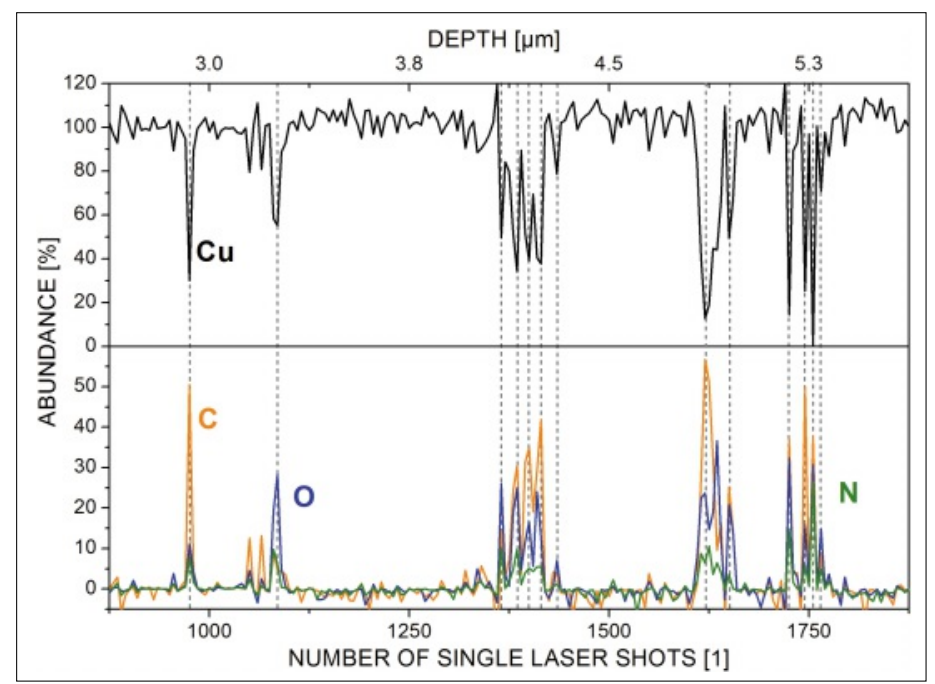

Fig. 6. Depth profiling section of the Cu film (sample S4) showing the anti-correlation between the major contaminants $\mathrm{C}, \mathrm{N}$, and $\mathrm{O}$ and $\mathrm{Cu} .{ }^{[4]}$ Reprinted with permission from Grimaudo et al. ${ }^{[4]}$ Copyright (2016) American Chemical Society.
200 nm per waveform. ${ }^{[32]}$ In this campaign the depth resolution was electronically limited, by the accumulation of 2'000 single laser shot mass spectra to one waveform. Accumulation of a reduced number of mass spectra would increase the depth resolution. The femtosecond laser system was used as ablation/ionisation source and a laser irradiance of about $5.5 \mathrm{TW} / \mathrm{cm}^{2}$ was applied for this measurement campaign (laser ablation crater with a diameter of about $15 \mu \mathrm{m}$ ).

The current measurement performance of LMS, including the used depth profiling measurement protocol, allowed the localisation of fossil veins even within the sam-

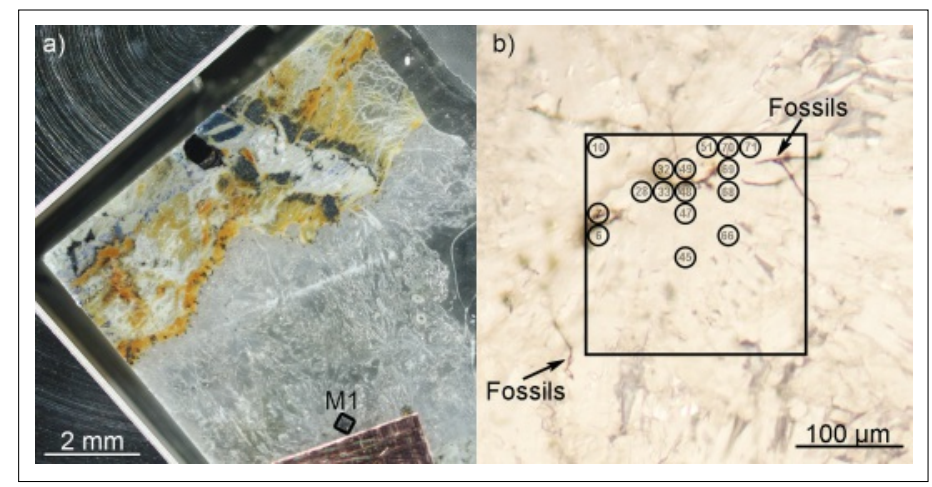

Fig. 7. Microscope image of a geological sample containing fossils of micrometre dimensions. The area marked by a black square (M1) in panel a) is shown enlarged in b). The black veins correspond to fossils embedded in the sample matrix. M1 was spot-wise investigated (100 single surface positions) using LMS. Image adapted with permission from Tulej et al. ${ }^{[32]}$ Copyright (2016) Mary Ann Liebert, Inc. 


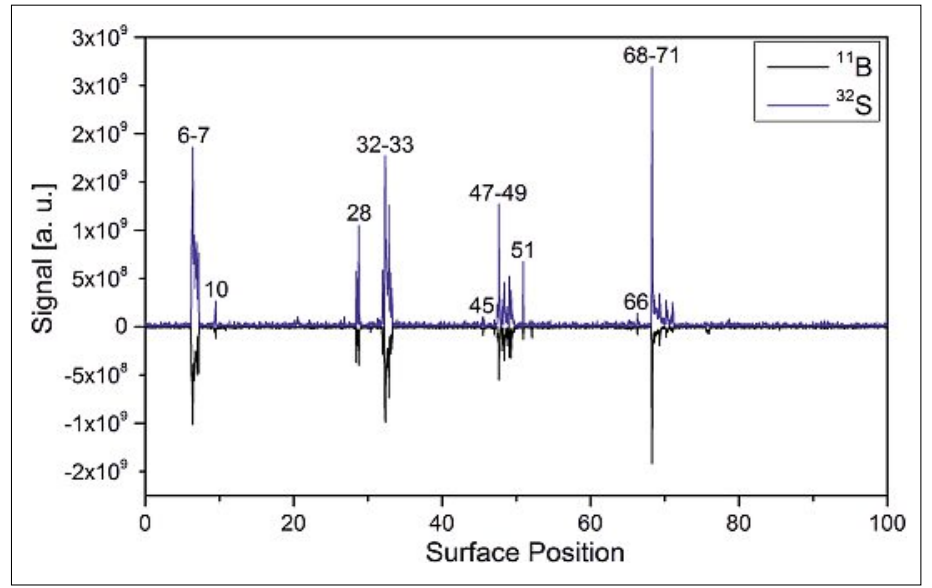
trometric measureImage adapted with

ple matrix where optical microscopes find their limitations. In Fig. 8 the signals from bio-relevant elements, B and S, are presented for the different surface positions. For this analysis all waveforms from each single surface position were accumulated to build one single mass spectrum and special attention was devoted to the $\mathrm{B}$ and $\mathrm{S}$ signals. Surface positions 45 and 66 turned out to contain bio-relevant elements (see Fig. 8), but no fossil veins were visible on these positions in the microscope image. Furthermore, the depth profiling procedure with LMS allowed these fossil signatures to be localised in the matrix within the depth profiling accuracy. ${ }^{[32]}$

\subsection{Three-dimensional Elemental Imaging of Bronze Alloys}

Alloys are used in various fields of research, ranging from applications within the microchip industry to technologies for energy conversion. ${ }^{[51-55]}$ Most recent measurements using the LMS instrument were conducted on $\mathrm{Cu}-\mathrm{Pb}-\mathrm{Sn}$ alloys containing different abundances of these three major elements. Mass spectrometric measurements with a lateral and vertical resolution within the micrometre and sub-micrometre regime, respectively, were conduct- ed to provide a $3 \mathrm{D}$ chemical record of the elemental distribution of $\mathrm{Cu}, \mathrm{Sn}$, and $\mathrm{Pb}$ within the alloys. For these measurements the femtosecond laser system was used as ablation/ionisation source whereas laser pulses of a few $\mathrm{TW} / \mathrm{cm}^{2}$ were focussed onto a surface area of about $10-15 \mu \mathrm{m}$ in diameter. The alloy surfaces were investigated by a $4 \times 4$ single-spot raster and up to 1'000 waveforms were recorded from each surface position, each an accumulation of 200 single laser shot mass spectra. ${ }^{[56]}$

In Fig. 9 preliminary analyses of the chemical depth profile (the first 500 waveforms, top of profile corresponds to the sample surface) are presented showing the spatial distribution of the elements $\mathrm{Pb}$, $\mathrm{Sn}$ and $\mathrm{Cu}$ at three different surface positions. ${ }^{[56]}$ While green indicates the expected elemental abundances according to the empirical formula $\left(\mathrm{Cu}_{80} \mathrm{Sn}_{10} \mathrm{~Pb}_{10}\right.$ alloy), blue and red show decreased or enriched elemental abundances, respectively. The accumulation over all mass spectrometric information from one raster experiment resulted in mean elemental abundances of about $(73 \pm 11) \mathrm{wt} \%,(8 \pm 4) \mathrm{wt} \%$ and $(19$ $\pm 10) \mathrm{wt} \%$, respectively for $\mathrm{Cu}, \mathrm{Sn}$ and $\mathrm{Pb}$. The latest results illustrate the possibility of applying LMS to investigate not only

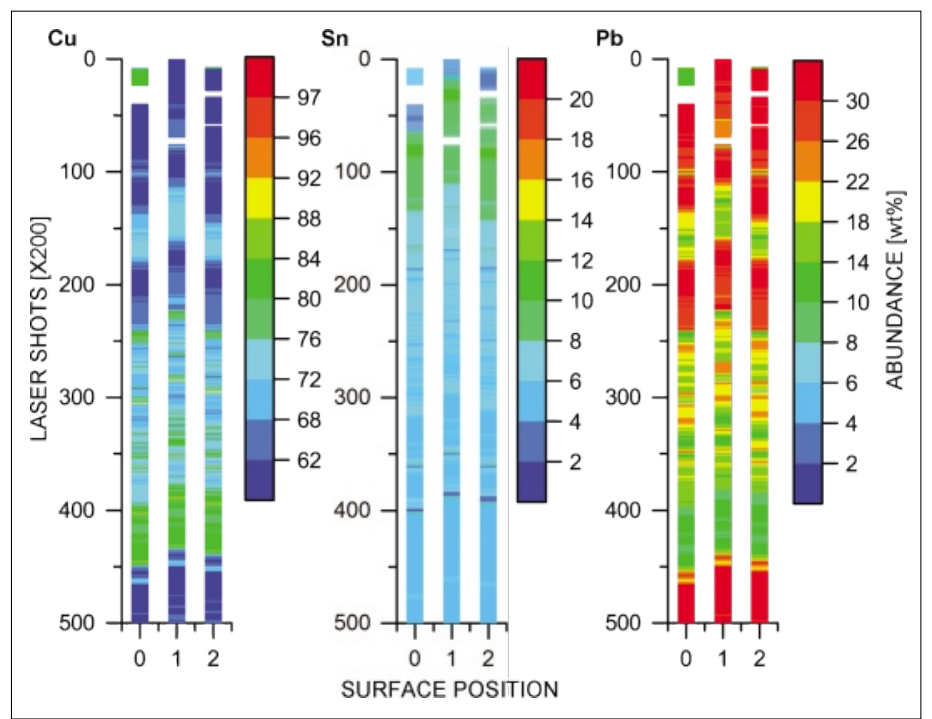

Fig. 8. The accumulation of all mass specments conducted on one surface position allowed to identify embedded fossils veins by monitoring bio-relevant elements, here $\mathrm{B}$ and $\mathrm{S}$. permission from Tulej et al. ${ }^{[32]}$ Copyright (2016) Mary Ann Liebert, Inc.

the elemental distribution at the surface of a material but also to get an insight into the homogeneity in all three dimensions giving evidence about the quality of the alloying material. ${ }^{[56]}$

\section{Conclusions}

Chemical analysis with high spatial resolution in the micro- and nanometre regime is of high interest in various fields of research, where detailed chemical insights within the solid material are necessary to e.g. further improve production processes. So far, measurement techniques such as SIMS, LA-ICP-MS and GD-MS have been used to conduct measurements with high spatial resolution. However, with the advances in the last decades regarding laser systems, electronics, and vacuum technology, LIMS has emerged as a truly alternative direct measurement technique with measurement capabilities comparable to the state-of-the art techniques. Nowadays LIMS instruments can conduct sensitive (ppb level) and quantitative mass spectrometric analyses of solid materials with a lateral resolution in the micrometre regime and a vertical resolution at the sub-nanometre level, both of considerable importance to provide a $3 \mathrm{D}$ chemical insight into the analyte of interest.

\section{Acknowledgments}

This work is supported by the Swiss National Science Foundation.

Received: January 15, 2016

[1] J. Pisonero, N. Bordel, C. Gonzalez de Vega, B. Fernández, R. Pereiro, A. Sanz-Medel, Anal. Bioanal. Chem. 2013, 405, 5655.

[2] A. Gutiérrez-González, C. González-Gago, J. Pisonero, N. Tibbetts, A. Menéndez, M. Vélez, N. Bordel, J. Anal. At. Spectrom. 2015, 30, 191.

[3] T. Noguchi, T. Nakamura, M. Kimura, M. E. Zolensky, M. Tanaka, T. Hashimoto, M. Konno, A. Nakato, T. Ogami, A. Fujimura, M. Abe, T. Yada, T. Mukai, M. Ueno, T. Okada, K. Shirai, Y. Ishibashi, R. Okazaki, Science 2011, 333, 1121.

g. 9. Preliminary depth profiling studies of bronze alloys are shown. By averaging all individual mass spectrometric measurements the nominal abundances of $\mathrm{Pb}, \mathrm{Sn}$ and $\mathrm{Cu}$ in wt $\%$ is derived. However, in certain applications the spatial distribution of incorporated elements are of high interest.
[4] V. Grimaudo, P. Moreno-García, A. Riedo, M. B. Neuland, M. Tulej, P. Broekmann, P. Wurz, Anal. Chem. 2015, 87, 2037.

[5] N. T. M. Hai, D. Lechner, F. Stricker, J. Furrer, P. Broekmann, ChemElectroChem 2015, 2, 664.

[6] S. J. M. Van Malderen, J. T. Van Elteren, F. Vanhaecke, Anal. Chem. 2015, 87, 6125.

[7] M. He, Y. Xiao, S. Zhang, R. Liu, W. Hang, B. Huang, Appl. Surf. Sci. 2015, 351, 624.

[8] R. Huang, B. Zhang, D. Zou, W. Hang, J. He, B. Huang, Anal. Chem. 2011, 83, 1102.

[9] J. S. Becker, 'Inorganic Mass Spectrometry - Principles and Applications', John Wiley \& Sons Ltd., England, 2007.

[10] J. Pantoja-Enríquez, E. Gómez-Barojas, R Silva-González, U. Pal, Sol. Energy Mater. Sol. Cells 2007, 91, 1392.

[11] M. Duta, S. Mihaiu, C. Munteanu, M. Anastasescu, P. Osiceanu, A. Marin, S. Preda, M. Nicolescu, M. Modreanu, M. Zaharescu, M. Gartner, Appl. Surf. Sci. 2015, 344, 196. 
[12] P. Le Coustumer, P. Chapon, A. Tempez, Y. Popov, G. Thompson, I. Molchan, N. Trigoulet, P. Skeldon, A. Licciardello, N. Tuccitto, I. Delfanti, K. Fuhrer, M. Gonin, J. Whitby, M. Hohl, C. Tanner, N. Bordel Garcia, L. Lobo Revilla, J. Pisonero, R. Pereiro, C. Gonzalez Gago, A. Sanz Medel, M. Ganciu Petcu, A. Surmeian, C. Diplasu, A. Groza, N. Jakubowski, R. Dorka, S. Canulescu, J. Michler, P. Belenguer, T. Nelis, A. Zahri, P. Guillot, L. Thérèse, A. Littner, R. Vaux, J. Malherbe, F. Huneau, F. Stevie, H. FrançoisSaint-Cyr, 'Analysis of thin and thick Films', in 'Mass Spectrometry Handbook', Ed. M.S. Lee, 2012, John Wiley \& Sons, Inc., Hoboken, NJ, USA.

[13] A. Riedo, V. Grimaudo, P. Moreno-García, M. B. Neuland, M. Tulej, P. Wurz, P. Broekmann, J. Anal. At. Spectrom. 2015, 30, 2371.

[14] B. Zhang, M. He, W. Hang, B. Huang, Anal. Chem. 2013, 85, 4507.

[15] Q. Yu, R. Huang, L. Li, L. Lin, W. Hang, J. He, B. Huang, Anal. Chem. 2009, 81, 4343.

[16] Y. Cui, J. F. Moore, S. Milasinovic, Y. Liu, R. J. Gordon, L. Hanley, Rev. Sci. Instr. 2012, 83, 093702.

[17] A. Riedo, M. Neuland, S. Meyer, M. Tulej, P. Wurz, J. Anal. At. Spectrom. 2013, 28, 1256.

[18] R. E. Russo, X. Mao, J. J. Gonzales, J. Yoo, Spectroscopy 2013, 28, 24.

[19] R. Hergenröder, O. Samek, V. Hommes, Mass Spectrom. Rev. 2006, 25, 551.

[20] X. Zeng, X. L. Mao, R. Greif, R. E. Russo, Appl. Phys. A: Mater. Sci. Process. 2005, 80, 237.

[21] R. E. Russo, X. Mao, J. J. Gonazales, S. S. Mao, Anal. At. Spectrom. 2002, 17, 1072

[22] D. J. Hwang, H. Jeon, C. P. Grigoropoulos, J. Yoo, R. E. Russo, App. Phys. Lett. 2007, 91, 251118.

[23] M. B. Neuland, S. Meyer, K. Mezger, A. Riedo, M. Tulej, P. Wurz, Planet. Space Sci. 2014, 101, 196.

[24] R. Huang, Q. Yu, L. Li, Y. Lin, W. Hang, J. He, B. Huang, Mass Spectrom. Rev. 2011, 30, 1256

[25] W. Hang, J. Anal. At. Spectrom. 2005, 20, 301.

[26] U. Rohner, J. A. Whitby, P. Wurz, Meas. Sci. Technol. 2003, 14, 2159.
[27] W. B. Brinckerhoff, G. G. Managadze, R. W. McEntire, A. F. Cheng, W. J. Green, Rev. Sci. Instr. 2000, 71, 536.

[28] W.B. Brinckerhoff, Planet. Space. Sci. 2005 , 53,817 .

[29] X. Li, W. B. Brinckerhoff, G.G. Managadze, D.E. Pugel, C.M. Corrigan, J.H. Doty, Int. J. Mass Spectrom. 2012, 32363.

[30] W. B. Brinckerhoff, Appl. Phys. A, 2004, 79, 953.

[31] G. G. Managadze, P. Wurz, R. Z. Sagdeev, A. E. Chumikov, M. Tuley, M. Yakovleva, N. G. Managadze, A. L. Bondarenko, Sol. Sys. Res. 2010, 44, 376.

[32] M. Tulej, A. Neubeck, M. Ivarsson, A. Riedo, M. B. Neuland, S. Meyer, P. Wurz, Astrobiol. 2015, 15, 669 .

[33] Y. Lin, Q. Yu, R. Huang, W. Hang, J. He, B. Huang, Spectrochim. Acta Part B 2009, 64, 1204.

[34] M. Tulej, M. Iakovleva, I. Leya, P. Wurz, Anal. Bional. Chem. 2011, 399, 2185.

[35] A. Neubeck, M. Tulej, M. Ivarsson, C. Broman, A. Riedo, S. McMahon, P. Wurz, S. Bengtsson, Int. J. Astrobiol. 2016, 15, 133.

[36] M. Tulej, A. Riedo, M. B. Neuland, S. Meyer, P. Wurz, N. Thomas, V. Grimaudo, P. MorenoGarcía, P. Broekmann, A. Neubeck, M Ivarsson, Geostand. Geoanal. Res. 2014, 38 , 441

[37] A. Riedo, A. Bieler, M. Neuland, M. Tulej, P. Wurz, J. Mass Spectrom. 2013, 48, 1.

[38] A. Riedo, S. Meyer, B. Heredia, M. B. Neuland, A. Bieler, M. Tulej, I. Leya, M. Iakovleva, K. Mezger, P. Wurz, Planet. Space Sci. 2013, 87, 1.

[39] M. Tulej, A. Riedo, M. Iakovleva, P. Wurz, Int. J. Spec. 2012, 2012, 234949-1.

[40] A. Bieler, K. Altwegg, L. Hofer, A. Jäckel, A. Riedo, T. Sémon, P. Wurz, J. Mass Spectrom. 2011, 46, 1143.

[41] A. Riedo, P. Wahlström, J. A. Scheer, P. Wurz, M. Tulej, J. Appl. Phys. 2010, 108, 114915-1.

[42] P. Moreno-García, V. Grimaudo, A. Riedo, M. Tulej, P. Wurz, P. Broekmann, Rapid Commun. Mass Spectrom. 2016, 30, 1031.

[43] Y. Liu, C. Chai, Chem. Geol. 1997, 141, 105.

[44] R. M. Housley, E. H. Cirlin, 'On the alteration of Allende chondrules and the formation of matrix', in 'Chondrules and their origins (A85-26528 11-91)', Houston, TX, Lunar and Planetary Institute, 1983, pp. 145-161.

[45] A. Stracke, H. Palme, M. Gellissen, C. Münker, T. Kleine, K. Birbaum, D. Günther, B. Bourdon, J. Zipfel, Geochim. Cosmochim. Acta 2012, 85, 114.

[46] H. Y. McSween Jr., G. R. Huss, 'Cosmochemistry', 2010, Cambridge University Press.

47] N. T. M. Hai, K. W. Krämer, A. Fluegel, M. Arnold, D. Mayer, P. Broekmann, Electrochim. Acta 2012, 83, 367

[48] N. T. M. Hai, J. Odermatt, V. Grimaudo, K.W. Krämer, A. Fluegel, M. Arnold, D. Mayer, P. Broekmann, J. Phys. Chem. C 2012, 116, 6913.

[49] K. Krischer, N. Mazouz, P. Grauel, Angew. Chem. Int. Ed. 2001, 40, 850.

[50] P. Strasser, M. Eiswirth, M. T. M. Koper, J. Electroanal. Chem. 1999, 478, 50.

[51] H.-A. Kuhn, I. Altenberger, A. Käufler, H. Hölzl, M. Fünfer, 'Properties of High Performance Alloys for Electromechanical Connectors (CH3)', in 'Copper Alloys - Early Applications and Current Performance Enhancing Processes', Ed. L. Collini, InTech, 2012.

[52] G. Zangari, Coatings 2015, 5, 195.

[53] C. Gütz, M. Selt, M. Bänziger, C. Bucher, C. Römelt, N. Hecken, F. Gallou, Tomás R. Galvão, S.R. Waldvogel, Chem. Eur. J. 2015, 21, 13878.

[54] C. Edinger, S. R. Waldvogel, Eur. J. Org. Chem. 2014, $2014,5144$.

[55] C. Edinger, V. Grimaudo, P. Broekmann, S. R. Waldvogel, ChemElectroChem 2014, 1, 1018.

[56] V. Grimaudo, P. Moreno-García, A. Riedo, M. Tulej, P. Broekmann, P. Wurz, Anal. Chem., to be submitted, 2016. 